\title{
Automatic Control of Rail Freight Transport
}

\author{
N. M. Legkiy ${ }^{*}$ \\ MIREA - Russian Technological University, Vernadskogo Av., 78, Moscow 119454, Russia
}

\begin{abstract}
In this paper, we have analyzed the results of development and implementation of an automatic identification system for the railroad freight cars intended to run on the Russian Railways. This identifier complies with the requirements of ISO 10374 standard and has improved performance in comparison to its prototypes.
\end{abstract}

\section{Introduction}

Today, there is a vital need to implement a monitoring system for the railroad freight cars in the railroad sector. The railway network has a special nature because of its size. Even though, the length of the Russian Railways is 1,5 times shorter than the U.S. rail infrastructure, the most freight volume is transported long distances throughout the Russian Federation. Occasionally, it happens that the rail freight car that was sent from a station may never again return to it. That is exactly why these special aspects have motivated to employ a location tracking system using passive RFID technology, even though the satellite navigation systems are much more accurate $[1,2]$. However, the tracking devices, quite often, require replacing power supplies and that makes its solution not so popular.

\section{Ease of Use}

While the Russian Federation was just considering the implementation of an automatic identification system for the railroad freight cars, other western countries have been already implemented RFID solutions to improve efficiency. The implementation delays led to the development of a modern railway transport infrastructure and allow to choose the best technology solutions. Namely, one of such solutions is passive Radio Frequency Identification (RFID) technology. The following factors such as the freight trains that run at fast speed between station-to-station blocks, insufficient reading time for the freight cars and a short distance to Europe have determined the range of ultra high frequency (UHF) and no request mode of operation for the system. By now the United States had already introduced the ISO 10374 standard [3] and there is a company that makes the systems using this standard [4]. Therefore, we decided to set up our own manufacturing.

We have developed the automatic identification system for the railroad freight cars (AISRFC), launched the production and implementation of the system [5].

\footnotetext{
* Corresponding author: legki@mirea.ru
} 
Fig. 1 shows AISRFC reader installed adjacent to rail tracks. Fig. 2 shows RFID identifier installed on the railroad car.

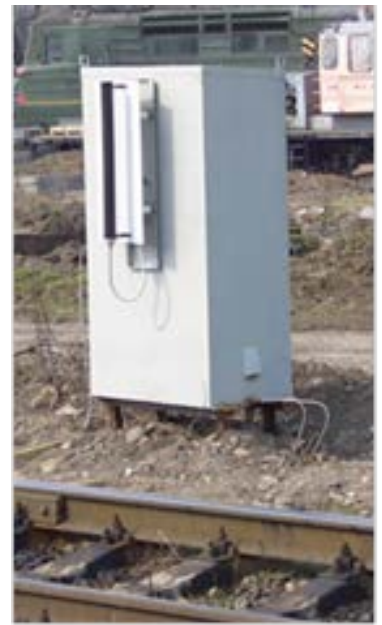

Fig. 1. AISRFC reader

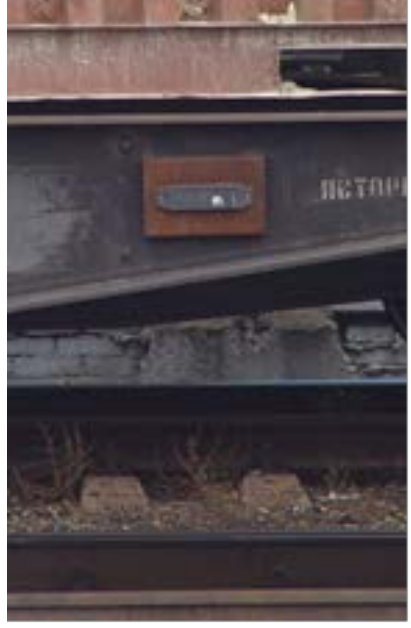

Fig. 2. RFID identifier installed on the railroad car

This sensor does not require any batteries to power it and is used as a passive modulated reflector of radio waves. So, an operating range of $\mathrm{Dp}$ is limited and can be calculated by using this radar equation (based on conditions in free space, the maximum radiation from a base station antenna that is directed to the maximum radiation of an antenna sensor):

$$
D_{p}=\frac{\lambda}{4 \cdot \pi} \cdot \sqrt{B S C \cdot S C} \cdot \sqrt[4]{\frac{T S}{R S \cdot m \cdot \sigma}}
$$

where $\lambda$ - is the operating wavelength;

Base Station Coefficient (BSC) - is the gain coefficient of the base station antenna;

Sensor Coefficient (SC) - the gain coefficient of the antenna sensor;

Transmitter Strength (TS) - is the pulse strength that the transmitter emits;

Reader Sensitivity $(R S)$ - is the reader receiver sensitivity;

$m-$ is the recognition coefficient to ensure the probability of correct detection;

$\sigma-$ is the probability of correct detection.

The signal strength that the antenna of identifier receives from the reader can be calculated by using the first or second order equation for radio frequency transmission line:

$$
P_{\text {identifier }}=\frac{P_{\text {reader }} G_{\text {reader }} G_{\text {identifier }}\left|F_{\text {reader }}\left(\varphi_{1}, \psi_{1}\right)\right|^{2}\left|F_{\text {identifier }}\left(\varphi_{2}, \psi_{2}\right)\right|^{2}|\xi|^{2} \lambda^{2}}{(4 \pi)^{2} R^{2}} \cdot L_{n} .
$$

The signal strength that is reflected from the identifier at the input of the reader antenna:

$$
P_{\text {identifier }}=\frac{P_{\text {reader }} G_{\text {reader }}\left|F_{\text {reader }}\left(\varphi_{1}, \psi_{1}\right)\right|^{2} \sigma_{\text {identifier }}|\xi|^{2} \lambda^{2}}{(4 \pi)^{3} R^{4}} \cdot L_{n} .
$$

According to the following ratios:

$P_{\text {reader }}, G_{\text {reader }}$ - are the power [W] and gain coefficient that the antenna reader emits;

$G_{\text {identifier }}$ - is the gain coefficient of the antenna identifier;

$F_{\text {reader }}\left(\varphi_{1}, \psi_{1}\right)$ - is the value of directional diagram based on the power of the antenna reader toward an object of identification; 
$F_{\text {identifier }}\left(\varphi_{2}, \psi_{2}\right)$ - is the value of directional diagram based on the power of the antenna reader;

$R$ - is the distance from the reader to the identifier;

$\lambda-$ is the wavelength;

$L_{n}-$ is an additional factor of signal loss that is reflected from the object or emitted by the source caused by the characteristics of the radio link;

$\xi$ - is the transmission coefficient with desired polarization based on the power:

$$
\xi=0,707\left(\vec{F}_{\text {reader }}\left(\theta_{1}, \varphi_{1}, \psi_{1}\right) \cdot \vec{F}_{\text {identifier }}\left(\theta_{2}, \varphi_{2}, \psi_{2}\right)\right)
$$

$\sigma_{a}$ - is equivalent to effective scattering surface of the antenna:

$$
\sigma_{a}=\frac{G_{\text {reader }}^{2} \lambda^{2}}{4 \pi} \cdot|\Gamma| \cdot\left|\xi^{2}\right|,
$$

where $|\Gamma|-$ is the reflection coefficient of the antenna identifier.

This coefficient is the source that transfers information from the identifier to the reader in RFID systems around $900 \mathrm{MHz}$ and higher read ranges.

So, by equation above it follows that

$$
P_{\text {identifier }}=k P_{\text {reader }},
$$

where $k$-is the scalar coefficient that determined by the wavelength, a distance, a position and transmitted/received signal sequences.

The power of $P_{\text {reader-reflector }}$ that is reflected by a tag and received by the reader, is related to the transmitted power by the following ratio:

$$
P_{\text {identifier }}=k^{2} P_{\text {reader }} \text {. }
$$

The design of the identifier looks interesting. Fig. 3 shows its structural design that was reengineered [5].

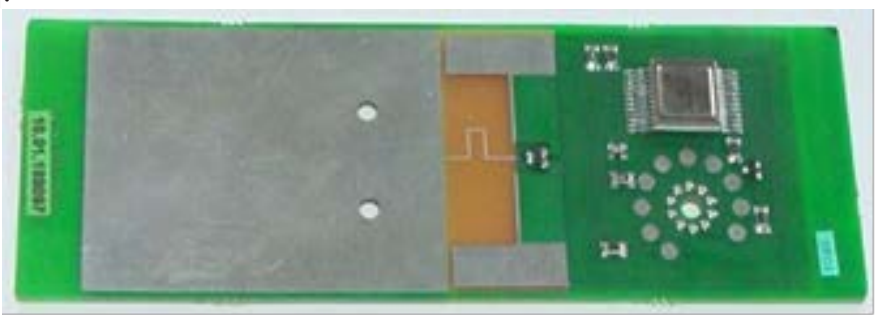

Fig. 3. A circuit board of the identifier

This identifier fully complies with the requirements of ISO 10374 standard. The design includes many advantages comparing to its prototypes [4]. Namely:

- It has much better and significantly affordable design for manufacturing, mainly due to lack of metallized through holes.

- It perfectly works for any metal surfaces and reads the object speed up to $200 \mathrm{~km} / \mathrm{h}$.

- It is reliable and works well with low power readers due to optimization of the input microstrip circuit.

Fig. 4 shows the frequency response of the new identifier that is measured by a method, which was patented [6]. Laboratory studies have confirmed that the identifier fully complies with all the standards and has improved performance in comparison to western prototypes, for example [7]. 


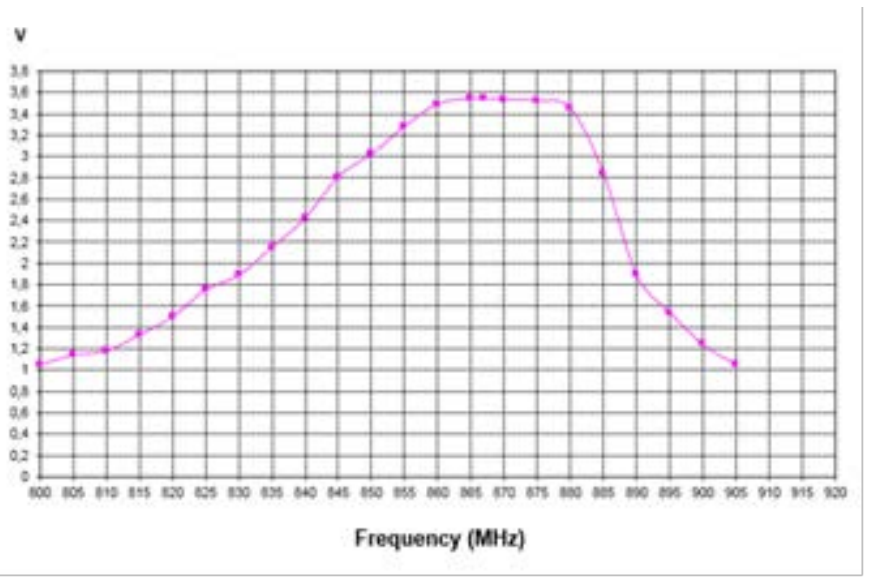

Fig. 4. The frequency response of the identifier

\section{References}

1. Rozenberg I.N., Cvetkov V. Ja. Global'nyj monitoring transportnyh ob"ektov // VESTNIK MGTU MIRJeA, \# 4, 2015, Tom II, s.184-195 (in Russ.).

2. Tretyakov V.A., Kulikov G.V., Lukyanets Y.F. Principles of creation of the big territorially distributed automated systems. Rossiiskii tekhnologicheskii zhurnal = Russian Technological Journal. 2020;8(1):34-42 (in Russ.).

3. ISO 10374 Freight containers - Automatic identification

4. www.transcore.com/rfid/rail-intermodal

5. Legkiy N. M. Avtomaticheskaja radiochastotnaja identifikacija zheleznodorozhnyh transportnyh sredstv: Monografija. - M. : Moskovskij gosudarstvennyj universitet putej soobshhenija, 2013. - 240 s. (in Russ.).

6. Patent RF 2254585, Kl. G01R29/10, Sposob kontrolja antennyh sistem / Legkiy N. M., Goshkov B. G., Krishtopov A.V., opubl. 20.06.05, bjul. \#17.

7. Rao et al., Impedance Matching Concepts in RFID Transponder Design, Fourth IEEE Workshop on Automatic Identification Advanced Technologies, 2005. 